\title{
Antihypertensive Treatment in the Elderly and Very Elderly: Always "the Lower, the Better?"
}

\author{
Alberto Mazza, ${ }^{1}$ Emilio Ramazzina, ${ }^{1}$ Stefano Cuppini, ${ }^{1}$ Michela Armigliato, ${ }^{1}$ \\ Laura Schiavon, ${ }^{1}$ Ciro Rossetti, ${ }^{1}$ Marco Marzolo, ${ }^{1}$ Giancarlo Santoro, ${ }^{1}$ \\ Roberta Ravenni, ${ }^{2}$ Marco Zuin, ${ }^{1}$ Sara Zorzan, ${ }^{1}$ Domenico Rubello, ${ }^{3}$ and Edoardo Casiglia ${ }^{4}$ \\ ${ }^{1}$ Department of Internal Medicine, "Santa Maria della Misericordia" Hospital, 45100 Rovigo, Italy \\ ${ }^{2}$ Department of Neuroscience, "Santa Maria della Misericordia” Hospital, 45100 Rovigo, Italy \\ ${ }^{3}$ Department of Nuclear Medicine, "Santa Maria della Misericordia" Hospital, 45100 Rovigo, Italy \\ ${ }^{4}$ Department of Clinical and Experimental Medicine, University of Padua, 35128 Padua, Italy
}

Correspondence should be addressed to Alberto Mazza, mazza.alberto@azisanrovigo.it

Received 14 July 2011; Accepted 25 July 2011

Academic Editor: Blas Gil Extremera

Copyright () 2012 Alberto Mazza et al. This is an open access article distributed under the Creative Commons Attribution License, which permits unrestricted use, distribution, and reproduction in any medium, provided the original work is properly cited.

\begin{abstract}
Arterial hypertension (HT) is age dependent and, with the prolongation of life expectancy, affects more and more elderly people. In the elderly, HT is a risk factor for organ damage and cardiovascular (CV) events. Both pharmacologic and nonpharmacologic reduction of blood pressure (BP) is associated with a corresponding decrease in systolic-diastolic or isolated systolic HT. Clinical trials have shown that BP lowering is associated with a decrease in stroke and other CV events. Therefore, BP reduction per se appears more important than a particular class of antihypertensive drugs. The benefit of antihypertensive treatment has been confirmed up to the age of 80 years, remaining unclear in the octogenarians. The benefit in lowering diastolic BP between 80 and $90 \mathrm{mmHg}$ is well established, while that of lowering systolic BP below $140 \mathrm{mmHg}$ requires further confirmations.
\end{abstract}

The lifespan increase during the last 30 years has resulted in a remarkable raise in the world population of people aged $\geq 65$ years [1]. Arterial hypertension (HT) is age dependent and, with the prolongation of life expectancy, affects more and more elderly people [2]. Approximately over $80 \%$ of the elderly have HT, mainly isolated systolic hypertension (ISH), defined in the European guidelines as systolic blood pressure (BP) $\geq 140 \mathrm{mmHg}$ and diastolic $\mathrm{BP}<90 \mathrm{mmHg}$ [3]. ISH is an age-related condition, as systolic BP increases with advancing age, while diastolic remains unchanged or even decreases after the sixth decade of life [4]. This phenomenon produces a progressive increase in pulse pressure (PP) [5]. $\mathrm{PP}$, the difference between systolic and diastolic BP, reflects the work increase due to systolic energy $[6,7]$.

In clinical practice, the decision to treat an elderly with HT depends on the answers to the following three questions

(i) Is HT a risk factor for stroke and cardiovascular (CV) events? (ii) Does non-pharmacologic and pharmacologic treatment reduce the risk of these events?

(iii) Which is the target to achieve in the elderly hypertensives?

The aim of this paper is to answer these questions, particularly focusing the discussion on whether the paradigm "the lower, the better" maintains a prognostic role in elderly and very old hypertensives.

In clinical trials completed before 1985, elderly hypertensive subjects were not included or represented a little component of the population under investigation [8]. At the beginning of the $90 \mathrm{~s}$, when the first epidemiological evidences documented the prognostic role of systolic BP $[9,10]$, many trials were performed in elderly hypertensives (Table 1). On the basis of the evidence provided by these trials, HT is now considered a well-established risk factor for stroke and CV disease in elderly people, and its treatment is considered as mandatory. 
TABLE 1: Efficacy of the antihypertensive treatment in stroke and cardiovascular events in different trials performed in the elderly.

\begin{tabular}{|c|c|c|c|c|c|c|c|c|}
\hline \multirow[t]{2}{*}{ Trial } & \multirow[t]{2}{*}{$\begin{array}{l}\text { Mean age at } \\
\text { randomization } \\
\text { (years) }\end{array}$} & \multirow[t]{2}{*}{$\begin{array}{l}\text { Subjects } \\
\text { enrolled }\end{array}$} & \multicolumn{2}{|c|}{$\begin{array}{l}\text { Mean } \mathrm{BP} \text { at } \\
\text { randomization } \\
(\mathrm{mmHg})\end{array}$} & \multirow[t]{2}{*}{ Drug treatment } & \multirow[t]{2}{*}{$\begin{array}{l}\text { Mean followup } \\
\text { (years) }\end{array}$} & \multirow[t]{2}{*}{$\begin{array}{c}\text { Stroke } \\
\text { Reduction (\%) }\end{array}$} & \multirow[t]{2}{*}{$\begin{array}{l}\mathrm{CV} \text { events } \\
\text { reduction }(\%)\end{array}$} \\
\hline & & & SBP & DBP & & & & \\
\hline Coope/Warrender & 68 & 884 & 196 & 99 & $\begin{array}{l}\text { Atenolol; } \\
\text { Bendrofluazide }\end{array}$ & 4,04 & -30 & - \\
\hline EWPHE & 72 & 840 & 183 & 101 & $\begin{array}{l}\text { HCTZ; } \\
\text { Triamterene; } \\
\text { Methyldopa }\end{array}$ & 8 & NS & -27 \\
\hline HYVET & 84 & 3845 & 173 & 91 & $\begin{array}{l}\text { Indapamide; } \\
\text { Perindopril }\end{array}$ & 2 & -30 & -34 \\
\hline MRC-HT & 70 & 4396 & 185 & 91 & $\begin{array}{l}\text { Atenolol; } \\
\text { HCTZ; } \\
\text { Amiloride }\end{array}$ & 5,8 & -31 & -35 \\
\hline SHEP & 72 & 4716 & 170 & 77 & Chlorthalidone & 4,5 & -36 & -32 \\
\hline STONE & 67 & 1632 & 180 & 90 & $\begin{array}{l}\text { Nifedipine } \\
\text { (Long-acting) }\end{array}$ & 2,5 & -57 & -60 \\
\hline STOP-HTN & 76 & 1627 & 195 & 94 & $\begin{array}{l}\text { Atenolol; } \\
\text { HCTZ; } \\
\text { Amiloride; } \\
\text { Metoprolol; } \\
\text { Pindolol }\end{array}$ & 5 & -47 & -40 \\
\hline Syst-China & 67 & 3000 & 171 & 86 & $\begin{array}{l}\text { Nitrendipine; } \\
\text { Captopril; } \\
\text { HCTZ }\end{array}$ & 2 & -38 & -37 \\
\hline Syst-Eur & 70 & 4695 & 174 & 85 & $\begin{array}{l}\text { Nitrendipine; } \\
\text { Enalapril; } \\
\text { HCTZ }\end{array}$ & 2 & -42 & -31 \\
\hline
\end{tabular}

SBP: systolic blood pressure; DBP: diastolic blood pressure; EWPHE: European Working Party on High blood pressure in the Elderly trial; HYVET: hypertension in the very elderly; MCR: Medical Research Council Hypertension Trial; SHEP: systolic hypertension in the elderly; STONE: Shanghai Trial of Hypertension in the Elderly; STOP-HTN: Swedish Trial in Old Patients with Hypertension; Syst-China: systolic hypertension in China; Syst-Eur: Systolic Hypertension in Europe; NS: not significant; HTCZ: hydrochlorothiazide.

In the elderly hypertensives, antihypertensive treatment is commonly recommended, but with high caution due to alterations in drug distribution and disposal, to presumptive changes in homeostatic CV control and to the quality of life that is typical of this age class. The randomized, controlled trials of antihypertensive treatment in the elderly have shown benefits comparable to those observed in younger or middleaged subjects. Not only this, but, as the baseline CV risk is higher in the elderly, the absolute benefit of treatment (expressed as number of events prevented per 1000 patientyears) is even higher in the elderly. However, most of the hypertensives enrolled in clinical trials were $<80$ years old.

The first evidence that antihypertensive treatment is also useful in subjects aged $\geq 80$ years is that published in 1999 by Gueyffier et al., concerning a subgroup of 1,670 very old subjects taking part of the INdividual Data ANAlysis of antihypertensive intervention trials (INDANA) [11]. In this meta-analysis, antihypertensive therapy led to a reduction in stroke $(-33 \%)$, CV morbidity $(-22 \%)$, and heart failure $(-39 \%)$. No significant effect was demonstrated for coronary events, and when the effect of treatment on fatal and nonfatal stroke was analyzed separately the benefit was limited to the nonfatal only. Ten years later, similar results were partially confirmed in the Hypertension in the Very Elderly Trial
(HYVET) over 3,845 subjects aged $\geq 80$ years and having high systolic BP [12], where all subjects were randomly assigned to placebo or active treatment with indapamide and perindopril was added in individuals who failed to meet the target $\mathrm{BP}$ of $150 / 80 \mathrm{mmHg}$. At two years of followup, mean $\mathrm{BP}$ was $15 / 6 \mathrm{mmHg}$ lower in subjects receiving active treatment than in those receiving the placebo, a difference that was associated with significant reduction of death from stroke, both fatal and non-fatal $(-30 \%)$, cardiovascular disease $(-23 \%)$, and heart failure $(-64 \%)$.

In the HYVET, a $21 \%$ reduction of the risk of overall mortality was also observed with active treatment. Nevertheless, the results of Bejan-Angoulvant's meta-analysis did not support those of the HYVET, showing comparable overall mortality in treated and untreated patients [13]. This discrepancy was outlined in the recent joint consensus developed by the American College of Cardiology Foundation and the American Heart Association [14]. The subjects enrolled in the HYVET were in good physical and mental condition and had low rate of previous CVD and therefore were not representative of very elderly.

Systolic HT ( $\geq 140 \mathrm{mmHg}$ ) and pulse HT ( $\geq 80 \mathrm{mmHg}$ ) [6] characterise the pressure profile of elderly hypertensives. It is therefore only natural that the intervention trials were 
focused on reducing systolic BP. The current ESH/ESC guidelines recommend reducing systolic BP below $140 \mathrm{mmHg}$ in grade 1-2 hypertensives having lowto-moderate total CV risk. Nevertheless, whether this recommendation also applies to elderly and very old subjects is unproved by outcome trials. In all trials [15-22] but one [23], elderly hypertensives randomized to more active treatment had lower incidence of $\mathrm{CV}$ events, but in no trial the systolic target $(<140 \mathrm{mmHg})$ was reached. The ACCOMPLISH [24] and the INVEST [25] studies showed no difference in antihypertensive effects when comparing drug treatment in subjects of age $\geq 80$ or $<80$ years, implicitly supporting the opportunity to treat very old subjects. Nevertheless, the Japanese Trial to Assess Optimal Systolic (JATOS) blood pressure in elderly hypertensive patients over-65-85-year-old subjects, (JATOS) demonstrated that a more strict BP control did not provide further benefit in reducing stroke, heart disease, vascular disease, and renal failure [23] and even showed a negative result on CV events suggesting a possible deleterious effect of intensive BP control in elderly hypertensives. This is not peculiar of old subjects, being in agreement with the results of the ACCORD trial [26] that showed no additional benefit of BP reduction-but only an increase in drugrelated adverse effects in-high-risk patients with diabetes mellitus $\geq 55$ years when targeting systolic at 120 rather than $140 \mathrm{mmHg}$. In addition, observational data from INVEST in hypertensive patients with coronary artery disease showed a J-curve pattern for adverse outcomes at on-treatment systolic BP of $135 \mathrm{mmHg}$ in patients aged 70 to 79 years and at $140 \mathrm{mmHg}$ for those aged $\geq 80$ years. This is not a new notation, as some retrospective analyses of intervention studies suggested [27] with exceptions [17-22] a J-curve trend of the risk of myocardial infarction in relation to treated BP. Also in a posthoc analysis of the EWPHE [15] it appears that in elderly hypertensives under active treatment total mortality had a U-shaped trend in relation to systolic $\mathrm{BP}$, with a nadir about $150 \mathrm{mmHg}$, whereas total mortality increased gradually with decreasing DBP from the upper tertile of $98 \mathrm{mmHg}$ (these results were partially flawed by the fact that a U-shaped trend with a nadir at $95 \mathrm{mmHg}$ was also found in the patients taking placebo, so that conclusive inferences cannot be drawn from this retrospective analysis). Finally, in the Hypertension Optimal Treatment (HOT) study [28], where $30 \%$ of the hypertensives were older than 65 years, it was found that the optimal BP for the lowest incidence of $\mathrm{CV}$ events was $138 \mathrm{mmHg}$ for systolic and $83 \mathrm{mmHg}$ for diastolic, with no significant improvement in $\mathrm{CV}$ end-points when BP was led to lower levels. The intention-to-treat analysis revealed a comparable pattern in the incidence of $\mathrm{CV}$ events in the adults and in the older patients, suggesting that optimal BP reductions are similar and independent of age.

Therefore, no trial evidence supports the guidelines recommendation to achieve a systolic target $<140 \mathrm{mmHg}$ in elderly subjects; in particular systolic values $<130$ and diastolic $<65 \mathrm{mmHg}$ should probably be avoided in the elderly.

In conclusion, particular attention should be paid to antihypertensive treatment of elderly hypertensives, which constitute a large, growing, and vulnerable part of general population. There is no doubt that antihypertensive treatment is justified by medical evidence. The assumption "the lower systolic BP, the lower the risk" is adequate for stroke and heart failure. Despite this, the best metaanalysis showed no clear results in decreasing total mortality by forcing antihypertensive treatment in very old subjects. In the randomized-controlled trials, elderly hypertensives were treated with diuretics, $\beta$-blockers, dihydropyridines calcium channel blockers, and converting-enzyme inhibitors. However, monotherapy normalizes BP in only $40-50 \%$ of cases, and therefore a combination of two or more drugs is often required to achieve the recommended BP goals. The most reasonable strategy is to start with a thiazide diuretic as first-line therapy and to optimize the maximal antihypertensive therapy with two drugs in low doses. The JNC, the WHO/ISH, and ESH/ESC guidelines recommend lowering BP in elderly hypertensives below 140/90 $\mathrm{mmHg}$. In this respect there are sufficient data that a diastolic BP between 80 and $90 \mathrm{mmHg}$ is associated with a clear benefit, except in case of coronary heart disease where a mortality increase was observed reducing diastolic BP below $80 \mathrm{mmHg}$.

\section{References}

[1] K. Christensen, G. Doblhammer, R. Rau, and J. W. Vaupel, "Ageing populations: the challenges ahead," The Lancet, vol. 374, no. 9696, pp. 1196-1208, 2009.

[2] R. H. Fagard, "Epidemiology of hypertension in the elderly," American Journal of Geriatric Cardiology, vol. 11, no. 1, pp. 23$28,2002$.

[3] G. Maneia, S. Laurent, E. Agabiti-Rosei et al., "Reappraisal of European guidelines on hypertension management: a European Society of Hypertension Task Force document," Journal of Hypertension, vol. 27, no. 11, pp. 2121-2158, 2009.

[4] E. Pinto, "Blood pressure and ageing," Postgraduate Medical Journal, vol. 83, no. 976, pp. 109-114, 2007.

[5] S. S. Franklin, V. A. Lopez, N. D. Wong et al., "Single versus combined blood pressure components and risk for cardiovascular disease the framingham heart study," Circulation, vol. 119, no. 2, pp. 243-250, 2009.

[6] E. Casiglia, V. Tikhonoff, A. Mazza, and A. C. Pessina, "Systolic and pulse hypertension," Aging Health, vol. 1, pp. 1-9, 2005.

[7] E. Casiglia, V. Tikhonoff, and A. C. Pessina, "Hypertension in the elderly and the very old," Expert Review of Cardiovascular Therapy, vol. 7, no. 6, pp. 659-665, 2009.

[8] Veterans Administration Cooperative Study Group on Antihypertensive Agents, "Effects of treatment on morbidity in hypertension. Results in patients with diastolic blood pressure averaging 115 through $125 \mathrm{mmHg}$," Journal of the American Medical Association, vol. 202, no. 11, pp. 1028-1034, 1967.

[9] H. M. Perry Jr., W. M. Smith, R. H. McDonald et al., "Morbidity and mortality in the Systolic Hypertension in the Elderly Program (SHEP) pilot study," Stroke, vol. 20, no. 1, pp. 4-13, 1989.

[10] S. MacMahon, "Antihypertensive drug treatment: the potential, expected and observed effects on vascular disease," Journal of Hypertension, vol. 8, no. 7, supplement, pp. S239-S244, 1990. 
[11] F. Gueyffier, C. Bulpitt, J. P. Boissel et al., "Antihypertensive drugs in very old people: a subgroup meta-analysis of randomised controlled trials," The Lancet, vol. 353, no. 9155, pp. 793-796, 1999.

[12] N. S. Beckett, R. Peters, A. E. Fletcher et al., "Treatment of hypertension in patients 80 years of age or older," New England Journal of Medicine, vol. 358, no. 18, pp. 1887-1898, 2008.

[13] T. Bejan-Angoulvant, M. Saadatian-Elahi, J. M. Wright et al., "Treatment of hypertension in patients 80 years and older: the lower the better? A meta-analysis of randomized controlled trials," Journal of Hypertension, vol. 28, no. 7, pp. 1366-1372, 2010.

[14] W. S. Aronow, J. L. Fleg, C. J. Pepine et al., “ACCF/AHA 2011 expert consensus document on hypertension in the elderly: a report of the american college of cardiology foundation task force on clinical expert consensus documents," Circulation, vol. 123, no. 21, pp. 2434-2506, 2011.

[15] A. Amery, W. Birkenhäger, P. Brixko et al., "Mortality and morbidity results from the European Working Party on High Blood Pressure in the Elderly trial," The Lancet, vol. 1, no. 8442, pp. 1349-1354, 1985.

[16] J. Coope and T. S. Warrender, "Randomised trial of treatment of hypertension in elderly patients in primary care," British Medical Journal, vol. 293, no. 6555, pp. 1145-1151, 1986.

[17] J. L. Probstfield, "Prevention of stroke by antihypertensive drug treatment in older persons with isolated systolic hypertension: final results of the Systolic Hypertension in the Elderly Program (SHEP)," Journal of the American Medical Association, vol. 265, no. 24, pp. 3255-3264, 1991.

[18] B. Dahlöf, L. H. Lindholm, L. Hansson, B. Schersten, T. Ekbom, and P. O. Wester, "Morbidity and mortality in the Swedish Trial in Old Patients with Hypertension (STOPHypertension)," The Lancet, vol. 338, no. 8778, pp. 1281-1285, 1991.

[19] S. Peart, P. J. Brennan, P. Broughton et al., "Medical Research Council trial of treatment of hypertension in older adults: principal results," British Medical Journal, vol. 304, no. 6824, pp. 405-412, 1992.

[20] J. A. Staessen, R. Fagard, L. Thijs et al., "Randomised doubleblind comparison of placebo and active treatment for older patients with isolated systolic hypertension," The Lancet, vol. 350, no. 9080, pp. 757-764, 1997.

[21] L. Liu, J. G. Wang, L. Gong, G. Liu, and J. A. Staessen, "Comparison of active treatment and placebo in older Chinese patients with isolated systolic hypertension," Journal of Hypertension, vol. 16, no. 12, pp. 1823-1829, 1998.

[22] H. Lithell, L. Hansson, I. Skoog et al., "The Study on Cognition and Prognosis in the Elderly (SCOPE). Principal results of a randomised double-blind intervention trial," Journal of Hypertension, vol. 21, pp. 875-886, 2003.

[23] JATOS Study Group, "Principal results of the Japanese trial to assess optimal systolic blood pressure in elderly hypertensive patients (JATOS)," Hypertension Research, vol. 31, pp. 21152127, 2008.

[24] K. Jamerson, M. A. Weber, G. L. Bakris et al., "Benazepril plus amlodipine or hydrochlorothiazide for hypertension in highrisk patients," New England Journal of Medicine, vol. 359, no. 23, pp. 2417-2428, 2008.

[25] S. J. Denardo, Y. Gong, W. W. Nichols et al., "Blood pressure and outcomes in very old hypertensive coronary artery disease patients: an INVEST substudy," American Journal of Medicine, vol. 123, no. 8, pp. 719-726, 2010.

[26] G. Mancia, "Effects of intensive blood pressure control in the management of patients with type 2 diabetes mellitus in the
Action to Control Cardiovascular Risk in Diabetes (ACCORD) trial," Circulation, vol. 122, no. 8, pp. 847-849, 2010.

[27] F. H. Messerli, G. Mancia, C. R. Conti et al., "Dogma disputed: can aggressively lowering blood pressure in hypertensive patients with coronary artery disease be dangerous?" Annals of Internal Medicine, vol. 144, no. 12, pp. 884-893, 2006.

[28] L. Hansson, A. Zanchetti, S. G. Carruthers et al., "Effects of intensive blood-pressure lowering and low-dose aspirin in patients with hypertension: principal results of the Hypertension Optimal Treatment (HOT) randomised trial," The Lancet, vol. 351, no. 9118, pp. 1755-1762, 1998. 


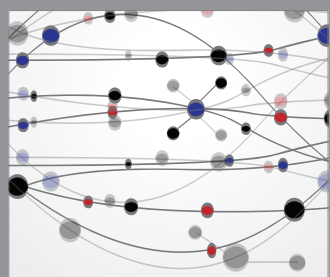

The Scientific World Journal
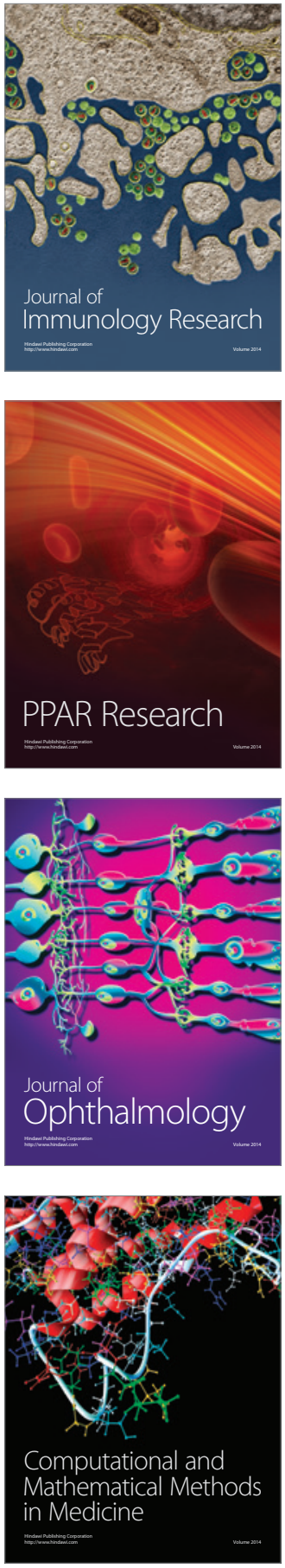

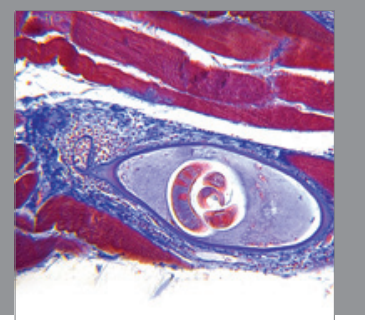

Gastroenterology

Research and Practice
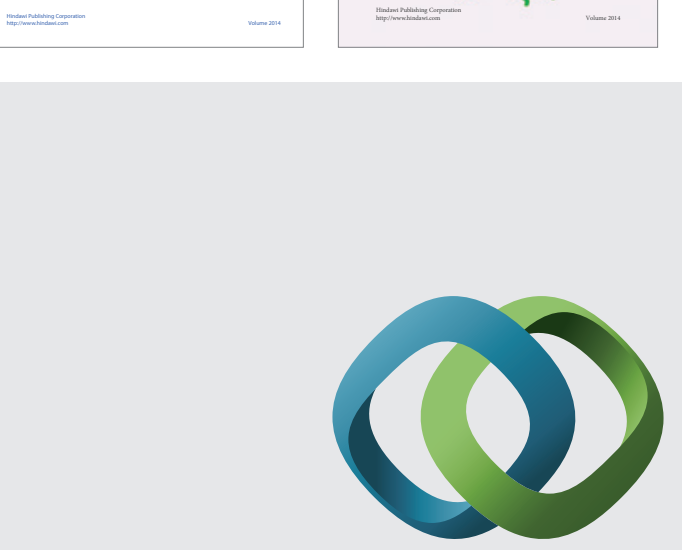

\section{Hindawi}

Submit your manuscripts at

http://www.hindawi.com
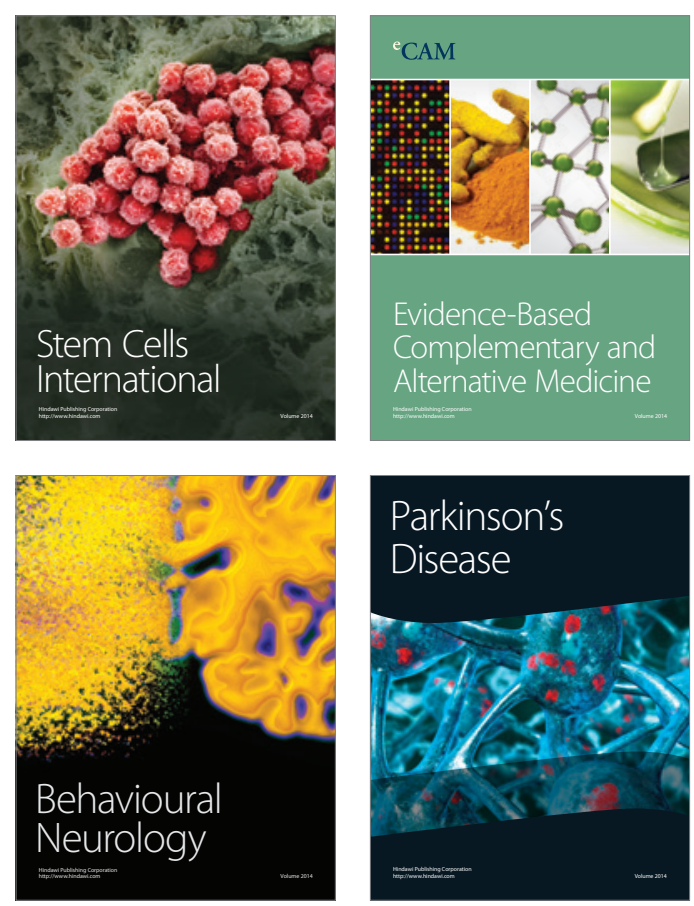

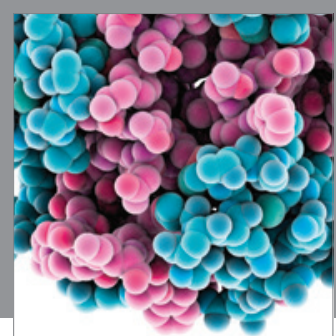

Journal of
Diabetes Research

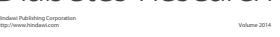

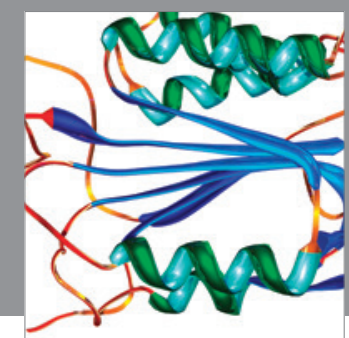

Disease Markers
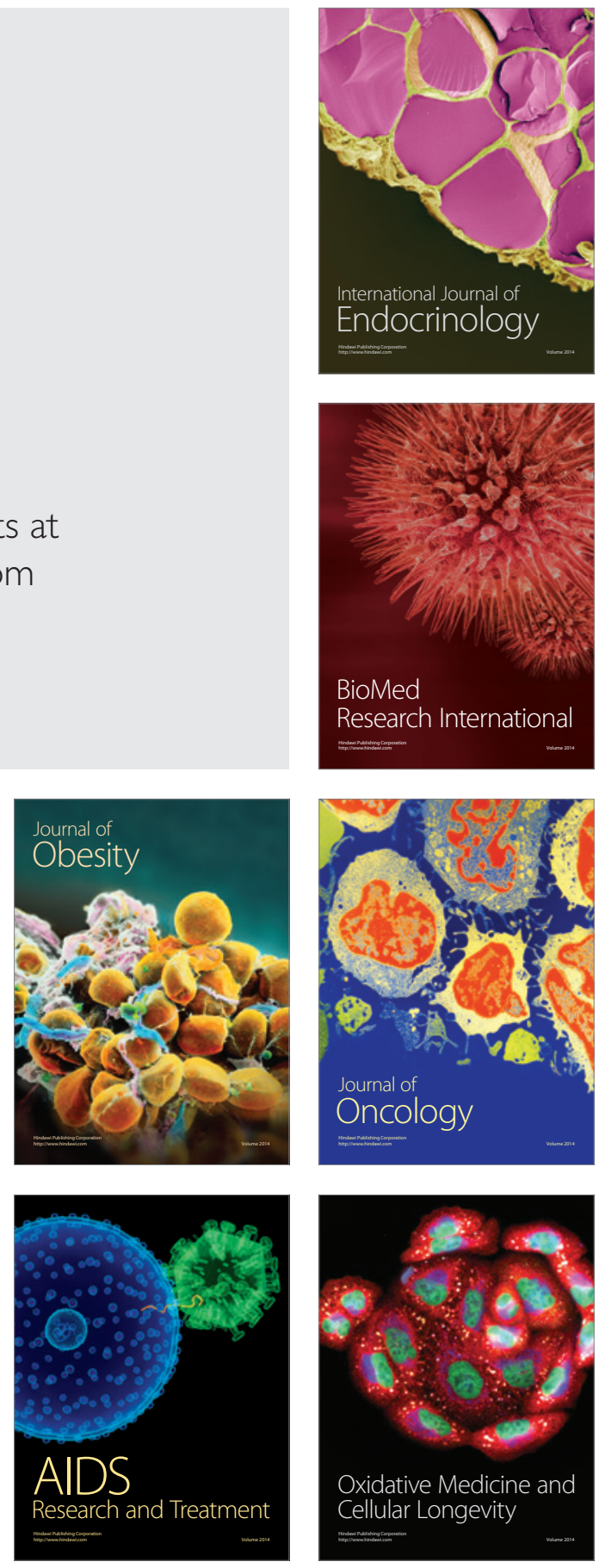